\title{
Apropiaciones y usos del pasado. Historia y patrimonio en el valle Calchaquí
}

Appropiations et usages du passé.

Histoire et patrimoine dans la vallée de Calchaquí

Appropriations and uses of past.

History and patrimony in Calchaqui valley

Lorena B. Rodríguez y Ana María Lorandi

\section{OpenEdition}

\section{Journals}

Edición electrónica

URL: http://journals.openedition.org/bifea/4979

DOI: $10.4000 /$ bifea. 4979

ISSN: 2076-5827

\section{Editor}

Institut Français d'Études Andines

\section{Edición impresa}

Fecha de publicación: 1 diciembre 2005

Paginación: 431-442

ISSN: 0303-7495

\section{Referencia electrónica}

Lorena B. Rodríguez y Ana María Lorandi, « Apropiaciones y usos del pasado.

Historia y patrimonio en el valle Calchaquí », Bulletin de l'Institut français d'études andines [En línea], 34

(3) | 2005, Publicado el 08 diciembre 2005, consultado el 04 diciembre 2020. URL : http://

journals.openedition.org/bifea/4979; DOI : https://doi.org/10.4000/bifea.4979

\section{(c) $(1) \&$}

Les contenus du Bulletin de l'Institut français d'études andines sont mis à disposition selon les termes de la licence Creative Commons Attribution - Pas d'Utilisation Commerciale - Pas de Modification 4.0 International. 


\title{
Apropiaciones y usos del pasado. Historia y patrimonio en el valle Calchaquí
}

\author{
Lorena B. Rodríguez \\ Ana María Lorandi**
}

\begin{abstract}
Resumen
Luego de dos experiencias de campo realizadas en el departamento de Santa María (sector sur del Valle Calchaquí, Argentina) y separadas en el tiempo por casi cuatro décadas, el objetivo de este artículo es reflexionar acerca de las apropiaciones y usos del pasado como elementos básicos del proceso de construcción de identidad. Entendiendo que dichos procesos son una producción simbólica, de carácter móvil y flexible y sometidos a una constante reelaboración, intentaremos comparar esas construcciones en dos momentos diferentes, analizando el rol que han tenido las escuelas, las instituciones políticas o el museo local, así como las disputas y la elaboración de identidades alternativas al discurso hegemónico.
\end{abstract}

Palabras clave: historia, patrimonio, identidad, usos del pasado

\section{Appropiations et usages du passé. Histoire et patrimoine dans la vallée de Calchaquí}

\section{Resumé}

Après deux expériences sur le terrain réalisées à Santa María (secteur sud de la Vallée de Calchaquí, Argentine) et séparées dans le temps par presque quatre décennies, le but de cet article est de réfléchir aux appropiations et usages du passé comme élément essentiel du processus de construction de l'identité. Si nous considérons ces processus comme une production symbolique aux caractéristiques mobiles,

Becaria de Doctorado. Universidad de Buenos Aires. Facultad de Filosofía y Letras. Instituto de Ciencias Antropológicas. Sección Etnohistoria. E-mail: rodriguezlo@hotmail.com

** Facultad de Filosofía y Letras, Universidad Nacional de Buenos Aires/ Consejo de Investigaciones Científicas y Técnicas (CONICET), Argentina. E-mail: alorandi_2000@yahoo.com.ar 
flexibles et soumises à une re-élaboration constante, nous tenterons de comparer ces constructions à deux moments différents, analysant le rôle joué par les écoles, les institutions politiques et le musée local, ainsi que les disputes et l'élaboration d'identité alternative au discours hégémonique.

Mots clés : histoire, patrimoine, identité, usages du passé

\title{
Appropriations and uses of past History and patrimony in Calchaqui valley
}

\begin{abstract}
After two fieldwork experiences in Santa María (south sector of Calchaqui Valley, Argentina) separated by almost four decades, the goal of this paper is to think about past appropriation and uses of the past as a basic element of identity construction. These processes are a symbolic production, with characteristics such as mobility and flexibility, and they submit to a constant re-elaboration. We confront these constructions at two different moments, analyzing the role of schools, political institutions and local museums as well as disputes and the elaboration of altertative identities to hegemonic discourse.
\end{abstract}

Key words: history, patrimony, identity, uses of past

Nuestra propuesta tiene como objetivo reflexionar acerca de las apropiaciones y usos del pasado como instancia constitutiva del proceso de construcción identitaria de los actuales pobladores del departamento de Santa María, provincia de Catamarca, Argentina y, al mismo tiempo, analizar la influencia que las políticas culturales de la zona tienen en este proceso. El departamento de Santa María se encuentra ubicado en el Valle de Yocavil o Santa María, nombres con los que se designa el sector sur de los Valles Calchaquíes. A fin de entender la problemática a abordar, es indispensable describir brevemente el contexto histórico general del que partimos.

En tiempos preincaicos, la región estuvo habitada por una numerosa población denominada genéricamente como diaguita, compuesta por una heterogénea cantidad de poblaciones de habla kakana. Compartían algunas pautas culturales, pero se organizaron en unidades políticas independientes con capacidad para confederarse ante riesgos comunes. Los papeles coloniales y la arqueología nos informan que el Inca, a pesar de haber ocupado y explotado la región, se enfrentó violentamente a las poblaciones diaguitas, debiendo movilizar e instalar a grandes contingentes de mitmaqkuna, cuyas funciones variaban desde el control político y militar de dichas poblaciones, hasta el reemplazo de los rebeldes en actividades productivas que estos parecen haber eludido parcialmente. Es así que, al llegar el español a los Valles Calchaquíes, debe enfrentarse con poblaciones políticamente fragmentadas, con cierta experiencia frente a un poder invasor y conformadas por un mosaico multiétnico; características que, sumadas a las 
altas montañas que los circundan, dificultaron la conquista del territorio. Comienza así una larga y cruenta historia colonial de resistencias y rebeliones que durará más de 130 años y que tendrá como consecuencia las «desnaturalizaciones» 1 de casi todas las poblaciones originarias del valle (Lorandi \& Boixadós, 1987-1988). O sea, el rasgo más original es que el valle se transforma en un espacio parcialmente despoblado, que será sometido a un nuevo proceso de colonización, diferente al del resto del noroeste argentino. Los valles fueron repoblados por familias que provenían de Atacama, del sur del Bolivia o de otras zonas aledañas y que aportaron mano de obra a las haciendas que se instalaron en la región. Salvo algunos antiguos indígenas que tuvieron acceso a sus tierras originales, $\mathrm{u}$ otros desplazados cuyos encomenderos obtuvieron autorización para reinstalarlos en los valles, el resto se compuso de migrantes que entablaron diversas formas de relaciones de producción con los nuevos dueños de la tierra.

Partiendo de este pasado histórico, una serie de preguntas se hicieron efectivas y sirvieron como ejes de investigación: ¿cómo construyen su identidad los actuales pobladores de Santa María? ¿Existe(n) apropiación(es) de este pasado al momento de construir la identidad? ¿Dicha apropiación es diferencial u homogénea? ¿Qué rol juega la escuela, el museo local y las instituciones políticas al momento de tipificar identidades?

\section{EL «SER SANTAMARIANO»: LA AUTOADSCRIPCIÓN, LOS OTROS Y EL PATRIMONIO INTANGIBLE}

Entendemos el concepto de identidad no como algo estático y monolítico, sino más bien como un proceso dinámico, siempre en reconstrucción e interactivo. Para entender estos procesos identitarios es fundamental tener en cuenta los mecanismos por los cuales un grupo determinado utiliza ciertas categorías de autoadscripción e identificación de los otros y organiza por ende la interacción entre los individuos (Barth, 1969). Este proceso no responde, por supuesto, en forma exclusiva a factores internos, sino que interactúa o reacciona ante presiones exógenas que irán modelando capas de identidad. Con el tiempo algunas de estas capas desaparecerán, otras quedarán en suspenso y otras persistirán y/o se remodelarán según las circunstancias.

Si bien sobre estos temas de patrimonio intangible es difícil (aunque no imposible) hacer un seguimiento histórico en zonas que dejan poca o ninguna documentación escrita o grabada que pueda recuperarse, sí es posible contrastar dos experiencias de trabajo de campo distanciadas por algunos decenios. Es, de alguna manera, la comunidad «revisitada» de Redfield. O sea, confrontaremos autoadscripciones e identificación de otros en dos períodos diferentes.

\section{1. La primera aproximación}

En la década de 1960 un equipo de arqueólogos, antropólogos e historiadores, realizó varias temporadas de trabajo de campo en los Valles Calchaquíes, en particular en el sector Yocavil o Santa María, en el marco de un Proyecto de Estudio Interdisciplinario de Área, financiado por la Facultad de Filosofía y Letras de la Universidad Nacional del Litoral 2 y del que participó como arqueóloga la autora senior de esta ponencia. ${ }^{3}$ En esta ocasión, nos referiremos a las experiencias

1 Por «desnaturalizaciones» entendemos el traslado forzado de poblaciones y su instalación en nuevas regiones. El caso más conocido es el de los quilmes, que fueron arrancados de los Valles Calchaquíes e instalados en la prov. de Buenos Aires en la actual localidad de Quilmes.

2 En la actualidad Facultad de Humanidades y Artes de la Universidad Nacional de Rosario.

3 Las investigaciones antropológicas que se realizaron en esa época se focalizaron principalmente en problemas del campesinado, más que en identificaciones étnicas y sus relaciones con la memoria histórica. A su vez los historiadores se ocuparon de problemas demográficos pero desde una perspectiva descriptiva y funcionalista, sin atender a los problemas migratorios ni profundizar en las identidades étnicas. Ver: AAVV, 1960; Cigliano, 1962; Meister, Petruzzi \& Sonzogni, 1963; Rasini, Ruggeroni \& Casaña, 1962-1963; Rasini, 1962-1963; Ruggeroni, 1962-1963; Ruggeroni, 1964; Antonioni, 1964. 
sobre la identidad de los pobladores de la zona, a partir de nuestros contactos con la población rural, mediada por los peones que colaboraban en las excavaciones arqueológicas y con quienes solíamos sostener largas e informales charlas, así como con la clase media urbana de la ciudad de Santa María con la que mantuvimos una estrecha relación social.

Es obvio que las investigaciones de los arqueólogos, cuyas experiencias estamos compartiendo con nuestros lectores, no tenían por objetivo profundizar el tema de la identidad. Pero, para nosotros, originarios del litoral «gringo» de la Argentina4, los pobladores de estos valles eran culturalmente diferentes, y la otredad de los santamarianos despertaba nuestra curiosidad, además de ser un asunto central desde la perspectiva antropológica.

En esos años, cuando se trataba de superar la identidad local santamariana, que constituía el primer nivel de identificación, la adscripción a la provincia de Catamarca, aparecía como la más relevante. El ser catamarqueño era una forma constante de autoidentificación, con fuerte carga de orgullo y hasta de desafío hacia algunas de las regiones colindantes. La oposición más notable se establecía con los tucumanos, sus vecinos más inmediatos, considerados ladrones y poco sinceros. Ambos sentidos, el de identidad y el de diferencia encierran una paradoja, vinculada a la ubicación geográfica del valle.

La provincia de Catamarca fue diseñada tardíamente en el proceso colonial. Su capital, San Fernando, fue fundada en 1683 y sólo a principios del siglo XVIII comenzó a poblarse en forma permanente. La jurisdicción otorgada a San Fernando fue constituida con territorios tomados de varias ciudades vecinas: de La Rioja, de Santiago del Estero y de Tucumán. El sector medio y sur del valle Santa María fue la porción que sustrajeron a San Miguel de Tucumán. Por razones de cercanía y comunicaciones, San Miguel sigue siendo la ciudad a la que los santamarianos recurren para comerciar, para estudiar o para atender su salud. En cambio, el valle se encuentra separado de San Fernando, capital de la provincia, por una larga travesía que debe sortear una serie de sierras que tienen dirección este-oeste y que separa al valle y en realidad lo aísla del resto de la provincia.

La paradoja, entonces, consistía en conservar un fuerte sentimiento de catamarqueñidad, sumado a la también fuerte diferencia con los tucumanos, a pesar del aislamiento del resto de Catamarca y de la proximidad y oportunidades que ofrecían los tucumanos. A su vez, las relaciones con otros sectores del valle o con el más septentrional valle Calchaquí eran escasas o nulas. En esos años, Calchaquí propiamente dicho al norte y Yocavil o Santa María al sur no tenían comunicación directa por carretera. La relación con la otra provincia próxima, Salta, se reducía a Cafayate, zona donde se encontraban ambos valles, pero no parece que hayan existido vínculos muy estrechos con Santa María, ni de éstos con el resto de esa provincia.

Cabe preguntarse entonces, qué factores intervenían para desarrollar ese fuerte sentimiento de identidad provincial. A nuestro entender había dos fundamentales. Uno era de tipo religioso, vinculado con el culto a la Virgen del valle de Catamarca donde se encuentra emplazada la ciudad de San Fernando. Virgen milagrosa, que convoca dos veces por año a las poblaciones de una amplia región (la región central) del Noroeste argentino. Los catamarqueños siempre se han sentido «dueños» de la imagen, y especialmente favorecidos por el milagro de su aparición en la zona. Constituye entonces, un factor que amalgama sentimientos de identidad, al menos desde el aspecto simbólico (Lorandi \& Schaposchnik, 1990).

El otro factor es de orden político. Durante los siglos XIX y XX se generó un fuerte clientelismo destinado a sostener la estructura institucional y política de la provincia como veremos luego con más detalles.

4 En Argentina la palabra «gringo» refiere a la población de origen europeo, especialmente italiano. 
Construida sobre tales variables, la población actual manejaba una memoria histórica de corto plazo que desconocía el dramático proceso de las desnaturalizaciones, salvo el episodio más relevante relativo al traslado del grupo étnico de los quilmes hasta Buenos Aires a fines del siglo XVII. Como la localidad de Quilmes queda en el único segmento del valle que aún pertenece a la provincia de Tucumán, los santamarianos no parecían asumir como propio ese proceso y confesaban ignorar que también los ocupantes del resto del valle habían sufrido extrañamiento similar, aunque con traslados menos espectaculares ${ }^{5}$.

Sin embargo, no podían ignorar y no ignoraban la existencia de abundantísimas ruinas arqueológicas (demostración de una notable densidad demográfica prehispánica) que habían sido el asiento de los indígenas. Pero no parecían hacerse preguntas sobre el destino de esos antiguos pobladores, que consideraban ajenos a su identidad o patrimonio de un pasado muy remoto. Suponían, vagamente, que el proceso de mestizaje y la aculturación los había transformado en la sociedad campesina actual.

Cuando excavábamos en Santa María en la década del 60 tampoco conocíamos los detalles de esa historia colonial6. Pero era evidente que existía una laguna temporal, un tiempo de nadie, entre el pasado más remoto con el que los santamarianos no se identificaban y la historia recordada, tal vez limitado al siglo en el que vivían.

Por otra parte, como ya lo dijimos, se observaban fuertes lazos políticos con la cabecera provincial. El gobernador Leónidas Saadi, de origen sirio, y fuertemente vinculado a la figura del presidente Perón, había construido un poder basado en el cacicazgo provincial y tenía fervientes seguidores entre los pobladores urbanos y rurales de Santa María. El clientelismo político, entonces, debió constituir un componente básico en el proceso de construcción identitario regional.

En los últimos años, durante el regreso del peronismo al poder, un hijo del viejo político, Ramón Saadi, renovó esos vínculos hasta que un difícil proceso criminal con implicancias políticas lo alejó del poder. Aparentemente, Santa María fue una de las ciudades que primero rompieron con el patronazgo tradicional y ese puede ser un factor más para comprender los cambios que se observan en la actualidad. Otro factor importante fue la construcción de la carretera por la quebrada de Las Flechas que ahora comunica el Valle Yocavil con el Calchaquí norte. La antigua integración prehispánica que no necesitaba de carreteras había quedado desarticulada cuando se comenzó a utilizar el automotor. En el presente la comunicación restaurada ha permitido reconstruir una identidad, que como veremos, une ambos sectores geográficos.

\section{2. La segunda aproximación}

Durante el año 2001, la autora junior de este trabajo realizó una investigación en la ciudad de Santa María destinada a analizar el problema de la identidad. Retomando el tema de las desnaturalizaciones indígenas, se abordó en una primera etapa el grado de conocimiento histórico y sus vínculos con la identidad local, entrevistando a maestros, profesores y estudiantes locales. La escuela fue, por lo tanto, el foco de las investigaciones. Lo que se expone a continuación es producto de esa prospección, pero que, a diferencia de la anterior, tenía como objetivo explícito la indagación sobre la identidad.

5 La mayor parte de la población del valle Yocavil fue trasladada al pie del monte tucumano o bien entregada a los españoles de La Rioja y de San Fernando de Catamarca que padecían de falta de mano de obra indígena. Se los repartió en grupos de no más de cinco o seis familias, de modo que no pudieron conservar su identidad original a partir de la segunda o tercera generación después de los traslados.

6 El equipo de investigaciones históricas se preocupó de problemas demográficos, partiendo de los registros parroquiales del siglo XVIII. Ellos no se interesaron en la historia colonial temprana, que fue abordada muchísimo años después por el equipo de Etnohistoria de la Universidad de Buenos Aires, al que pertenecen las autoras de este trabajo. Respecto de los trabajos de este equipo puede consultarse Lorandi, 1997. 
Contradiciendo lo que se había observado en la década del sesenta, lo que primero llamó la atención fue que los pobladores de Santa María, que se autoadscribieron en primera instancia como santamarianos, constituyeron como su «otro», por antonomasia, a los pobladores del Valle de San Fernando, capital de la Provincia de la cual los santamarianos forman parte.

Más adelante veremos cómo esta autoidentificación tiene rasgos o características bien delimitadas. Ahora bien, ¿en base a qué elementos, prácticas, significados, elaboran esta diferencia identitaria? Es importante destacar que esta identidad santamariana encuentra entidad en lo que ellos denominan sus «tradiciones», o, como lo llamamos nosotros, el patrimonio intangible` o más ampliamente, como lo denomina Ratier, patrimonio social o vivo8. Estas tradiciones, patrimonio intangible o patrimonio vivo, permiten sustentar los sentidos de pertenencia; es decir, constituir un «nosotros» en contraposición a un «otros». Historias, mitos, leyendas, Pachamamas, apachetas, indios, gauchos, aparecidos, fantasmas, brujas, duendes, etc., se mezclan todos en una suerte de «teatralización» del ser santamariano, que sin ninguna duda es fuertemente mestizo. De todas maneras, si bien sus tradiciones conforman un cúmulo y yuxtaposición de prácticas y usos diversos, aparece con mucha fuerza — aunque creemos que se trata de un proceso bastante reciente- la idea de recuperar, revalorar y hasta volver al pasado indígena.

Si bien se autoadscribieron como santamarianos y según ellos con características propias, bien delimitadas, también insistieron con preocupación en que la cultura del santamariano era muy mezclada, impura e inauténtica y plantearon la necesidad de volver a ser algo que ya no son, de recuperar un pasado ideal, culturalmente puro y auténtico. Conviene entonces preguntarnos: ¿cuáles son entonces las prácticas, los elementos, el acervo histórico y cultural que constituye la verdadera esencia —auténtica y pura- del ser santamariano? ¿Qué es lo que, «a pesar de todo, está latente» (como lo expresa un informante) y que hay que reflotar, recuperar y valorar? Ante la falta de conocimiento detallado sobre el dramático proceso colonial al que fueron sometidos los indígenas, han optado por manifestar una preocupación general por recuperar sus tradiciones y el pasado prehispánico, valorar sus formas de vida, sus costumbres y prácticas. Lo interesante de este proceso no es determinar cuán auténtica es la figura del indígena al que quieren rescatar del pasado, sino por el contrario, tratar de rastrear y entender los procesos por los cuales ciertas prácticas, tradiciones, memorias, etc. han adquirido o están adquiriendo autenticidad, convirtiéndose por ende en puras e incólumes.

\section{2. 1. El rol de las escuelas, el museo local y las instituciones políticas}

Para entender cómo es que la figura del indígena — figura que no siempre ha gozado de buena salud- está constituyéndose en ícono del ser santamariano, es interesante ver el problema desde otros ángulos. La idea de considerar el discurso escolar como discurso hegemónico, nos hizo pensar que la escuela estaría cumpliendo un rol esencial al momento de rescatar el pasado indígena de la zona y constituirlo en un bien preciado, valorado y fundante de la «santamarianidad». Por el contrario, aunque a partir de la Reforma Educativa de 1995 se deja cierto espacio y hasta se incentiva la inclusión en las currículas de los docentes de temáticas

7 «Podría definirse el patrimonio intangible como el conjunto de formas de cultura tradicional y popular o folclórica es decir, las obras colectivas que emanan de una cultura y se basan en la tradición. Estas tradiciones se trasmiten oralmente o mediante gestos y se modifican con el transcurso del tiempo a través de un proceso de recreación colectiva. Se incluyen en ellas las tradiciones orales, las costumbres, las lenguas, la música, los bailes, los rituales, las fiestas, la medicina tradicional y la farmacopea, las artes culinarias y todas las habilidades especiales relacionadas con los aspectos materiales de la cultura, tales como las herramientas y el hábitat». (www.unesco.org)

8 «Nos inclinamos más hacia la designación de patrimonio vivo, en oposición a un patrimonio muerto que estaría constituido por objetos y testimonios inanimados sin vigencia actual [...] Patrimonio vivo o social [...] es la cultura vigente, en movimiento, transformada y transformante, es decir ese conjunto de relaciones sociales y sus productos que constituyen el objeto empírico sobre el cual ejerce su tarea investigativa la antropología social». (Ratier, 1988:26). 
relativas a lo regional, a la historia colonial de la zona o un abordaje detallado de los aborígenes de la región, estos aspectos se diluyen en la idea de una nación homogénea y compacta ${ }^{9}$. Como lo expresa claramente Mónica Quijada, el problema de homogeneización de los estados nacionales produjo un movimiento de exclusión para cualquier manifestación cultural ajena o diversa al paradigma que intentaba imponerse (Quijada, 2001). Concretamente, las currículas de los docentes no mostraron una gran preocupación por abarcar estas temáticas, aunque muchos de ellos, incluyendo los directores de los establecimientos, estuvieron —al momento de las entrevistas - preocupados por «rescatar del olvido» esos temas.

Es interesante notar que si bien las problemáticas referidas no son abordadas formalmente dentro de las instituciones educativas, existen varios espacios extraescolares en los cuales sí se retoman temas que tienen que ver con la historia regional, y como algunos de ellos los llamaron, temas relativos al «rescate de la memoria». Estos ámbitos o espacios a los que nos referimos, son el museo local «Eric Boman» y la Secretaría de Cultura y Turismo de Santa María, instituciones que desde hace un tiempo, trabajan de manera conjunta y que tienen como finalidad «revalorizar la cultura indígena».

El museo local «Eric Boman» exhibe una rica muestra de restos arqueológicos correspondientes a todos los períodos. Si bien dicho museo funciona hace muchos años en la zona, solo recientemente y de acuerdo con los objetivos de la Secretaría, ha implementado una política de puertas abiertas a la comunidad, ofreciendo charlas, asesoramiento y visitas guiadas a los sitios arqueológicos. El museo de Santa María, como casi todos los museos, funciona como espacio ritual; en palabras de García Canclini:

«[...] el museo se vuelve ceremonial por el hecho de contener los símbolos de la identidad, objetos y recuerdos [...] algo que ya no existe pero es guardado porque alude al origen y a la esencia. Allí se conserva el modelo de la identidad, la versión auténtica». (García Canclini, 1995: 178).

Como lo plantearon los mismos actores sociales, lo verdadero, lo auténtico, lo esencial, es para los santamarianos el pasado indígena.

La Secretaría de Cultura y Turismo, por su parte, ha encaminado un gran programa de «rescate» que pareciera tener básicamente objetivos turísticos. Así es que un agente de dicha Secretaría nos decía:

«[...] lo cultural se relaciona con el turismo, la política es "marketinizar" para revalorizar a los valles como destino y ofrecer sus productos turísticos: la identidad cultural indígena, económica $[. .]$.

Para avanzar en esta línea, se ha constituido el «Ente Regional de los Valles Calchaquíes», cuyos fundadores son las municipalidades de Santa María (prov. de Catamarca), Tafí del Valle (valle colindante hacia el este, provincia de Tucumán) que incluye el poblado Amaicha ubicado en el de Yocavil y Cafayate (prov. de Salta). Más tarde se asociaron al Ente las restantes comunas de casi todos los pueblos de ambos sectores de los valles. En su artículo 1ํㅡ, el estatuto del Ente establece que la finalidad del mismo es:

«[...] promover y coordinar la actividad turística recreativa y productiva, oficial y privada, sobre la base de objetivos y políticas concordantes y concurrentes al desarrollo económico y social armónico de la región, y con el fin de crear una imagen única,(subrayado nuestro) promocionar e impulsar el crecimiento de los Valles Calchaquíes en su conjunto»10.

9 Desde la segunda mitad del siglo XIX — momento en que se constituye y organiza el estado-nación argentinola escuela y en especial la asignatura de Historia, funcionaron como elementos indispensables para crear una conciencia e identidad nacional. Hoy la escuela, a pesar de las transformaciones y cambios sufridos a partir de la última reforma educativa, sigue poniendo énfasis en estos temas. La institución escolar en Santa María, al menos en aquellas en las que pudimos trabajar, no escapa a esta regla.

10 Documento provisto por la Municipalidad de Santa María. 
Entre las acciones que le corresponden llevar adelante, el Ente se propone proteger el medio ambiente en todos sus aspectos y resguardar el patrimonio arqueológico, histórico y artesanal de la región. El resto de los objetivos particulares están enderezados al fomento de turismo, mediante construcción de carreteras, alojamientos, organización de circuitos turísticos y relaciones con otros entes de promoción similares. Si bien se establece que deberán formarse guías turísticos idóneos, no se expresan directivas precisas en ese sentido.

$\mathrm{Al}$ respecto es interesante notar que este proceso de convertir al patrimonio - tangible e intangible- en una estrategia de marketing, no es un fenómeno novedoso. En las últimas décadas hemos asistido a un proceso de «culturización» de las políticas. La cultura, categoría que de por sí se presta al debate, está presente en todas las agendas de gobiernos locales y empresas, y el caso de Santa María no es una excepción.

La misma Secretaría está encarando una serie de obras monumentales que tienen como base la representación de iconografías y simbolismos indígenas. Así por ejemplo, en la entrada de la ciudad se modeló una enorme Pachamama de material que ha generado una encendida polémica entre los pobladores. Para ellos esta imagen —una joven y voluptuosa mujer embarazada - no representa a la Madre Tierra, a quien ellos asocian a una viejita, de largos cabellos y extremadamente delgada. Al parecer, la imagen de esta Pachamama proviene de Amaicha, lugar en donde todos los años, durante el mes de febrero, se elige entre todas las mujeres mayores del lugar a la reina de la Fiesta, es decir, la Pachamama de ese año11. Al preguntarse por esta disconformidad, la gente de la Secretaría contestó:

«[...] hay una falta de conocimiento profundo de la gente, el festival de Amaicha de donde viene esa imagen que la gente tiene de la Pachamama, es un festival folklórico, una versión aculturizada, tiene que ver con lo gauchesco, con lo hispánico, se revaloriza el acervo folklórico pero no del aborigen [...] Hay que retomar otro sentido [...]»

La identidad del santamariano, dijimos, se sustentaba en las tradiciones, principalmente en tradiciones relacionadas a los antiguos pobladores de la zona: los diaguitas. Dijimos también que esta preocupación general por recuperar la figura del indígena, parece ser parte de un reciente proceso, en el que se descartan algunos elementos — por ejemplo la figura del gaucho- y se retoma con fuerza un nuevo ícono. Nos preguntamos entonces iqué rol han jugado el museo y la Secretaría en este proceso? ¿La recuperación del pasado indígena como fundamento de la identidad santamariana es sólo consecuencia de las recientes políticas implementadas en la zona o por el contrario esas políticas reflejan necesidades de la población que hasta el momento no habían sido atendidas? ¿Tanto la Secretaría de Cultura y el museo, como los diversos pobladores recuperan la misma figura del indígena y su pasado o más bien se observan apropiaciones diferenciales, alternativas?

En este punto, es importante reforzar la idea de que existen luchas, confrontaciones, tensiones y competencias por la apropiación del sentido. No podemos perder de vista que si bien hay clasificaciones hegemónicas o dominantes, que irán orientando y de alguna manera «determinando aquello que integra y aquello que se excluye del patrimonio cultural [...]» (Ratier, 1988: 27), siempre existen alternativas contrahegemónicas.

11 Todos los años, durante tres días consecutivos en el mes de febrero, se festeja, en Amaicha del Valle, la Fiesta de la Pachamama. Miles de adoradores de la Madre Tierra, así como curiosos y turistas, se acercan al lugar para rendirle homenaje. Uno de los momentos más emotivos es cuando se da a conocer el nombre de la anciana que representará ese año a la Pachamama. Una vez elegida, la Madre Tierra recibe los atributos y es entronizada en un asiento de piedra cubierto por ponchos. 


\section{2. 2. Apropiar diferencialmente el pasado: los rebeldes santamarianos}

Anteriormente nos preguntábamos acerca del peso que tendrían las instituciones políticas como formadoras o tipificadoras de identidad. No podemos dejar de poner el acento en la idea de que la Secretaría de Cultura y Turismo junto con el museo local, encaran —entre otras cosasun proyecto turístico que hemos mencionado y que está destinado a satisfacer a decenas de visitantes que suponen ávidos de «cultura indígena». La investigación llevada a cabo no nos permite calcular el peso que estas instituciones han tenido al momento de edificarse la identidad santamariana en relación a este pasado indígena, pero el hecho de que el Presidente de la Nación (Fernando de la Rúa) se haya trasladado a Santa María en el mes de agosto de 2001 e inaugurado el monumento a la Pachamama se torna significativo.

Al respecto es interesante el siguiente planteo teórico:

«[...] la puesta en valor de ciertos elementos del patrimonio social de las clases subalternas en la consideración de la sociedad global depende del papel de sus portadores en el contexto general de las luchas sociales del momento. En el plano simbólico se verifican una serie de mecanismos de legitimación y exclusión de bienes culturales y de resignificación ideológica de éstos, de lo que resultará la configuración de aquello que es socialmente aceptado como el patrimonio vivo [...] Veremos cómo muchas veces se fuerza el pasaje de esos bienes desde el patrimonio vivo al muerto a través de expedientes que pueden incluir el genocidio liso y llano o la desautorización académica, según las circunstancias». (Ratier, 1988: 27).

Si tuviéramos espacio para hacer un recorrido histórico acerca del uso que los sectores hegemónicos han hecho de la figura del indio o del gaucho (véase por ejemplo Ratier, 1988 y Rodríguez Molas, 1982), podríamos entender más claramente los procesos por los cuales dichos sectores se apropian y dan valor a ciertos elementos del patrimonio en detrimento de otros. Si bien para el caso de Santa María no conocemos detalles de cómo pueden haber sido estos procesos para épocas anteriores, creemos que la insistencia actual en recuperar el pasado indígena de la zona como hecho fundante de la identidad, es en parte consecuencia de intereses políticos que van más allá de los de los pobladores locales.

Aparentemente en el lapso que transcurre entre la década del 60 y el presente, se produjeron varios fenómenos culturales ligados a procesos identitarios que los antropólogos rosarinos no pudieron observar. Así como en la década del 1970, el pasado ideal, auténtico, puro y probablemente más rentable pudo ser el del gaucho — concretamente hablamos de los gauchos santamarianos-12, que probablemente ha sido tomado de los sectores vallunos correspondientes a la provincia de Salta, que ensalza particularmente a sus «gauchos de Güemes» que defendieron la frontera contra los ejércitos españoles en los albores de la independencia. En la actualidad, los sectores hegemónicos recuperan al indígena y específicamente su cultura y los valorizan y legitiman, al punto de conformar el núcleo del patrimonio de la zona. Por otra parte, si hacemos un recorrido a través de la historia legislativa argentina en torno a la problemática indígena (véase Briones \& Carrasco, 1996), podemos observar también cómo según cada momento, tipo de gobierno y situación política, el indígena se articula jurídicamente al país. En el caso concreto de nuestro país, Argentina fue adecuándose lentamente a la normativa internacional respecto de las poblaciones indígenas. A fines del año 1993 se promulga la ley nacional 24309 para reformar

12 El diez de noviembre de 1975 se crea la Asociación de Gauchos Santamarianos. Es curioso observar que unos meses después también comienza la dictadura militar en Argentina, época en que si había que buscar un ícono de identidad jamás podría haber sido el indio. La figura del gaucho, en cambio, a pesar de que en sus orígenes haya sido desvalorizada, ha constituido sobre todo a partir de las Guerras de la Independencia, un elemento importante de la nacionalidad, casi en un símbolo patrio. Una figura que nace en la marginalidad fue ocupando, a medida que desaparecía físicamente, un lugar simbólico destacado como ícono de la argentinidad. En este proceso, los sectores dominantes cumplieron un rol fundamental. No es extraño pensar que en Santa María, haya sucedido algo semejante. 
la Constitución Nacional de 1853 y es recién en 1994, con la reforma de la Constitución Nacional, en el artículo 75, inciso 17, que se reivindican las comunidades aborígenes. A partir de ese momento, dicha problemática comienza a ocupar un lugar destacado en la legislación nacional. Si bien estos cambios no deben leerse como la causa por la cual en Santa María se está reconstruyendo la identidad alrededor del pasado indígena de la zona, sí creemos es un elemento importante que permite tanto a autoridades locales como a los pobladores, otorgarle carácter de patrimonio legítimo ${ }^{13}$.

Ahora bien, ¿̇uál es el indígena que estas instituciones intentan ensalzar? La figura del indígena que intenta recuperar tanto la Secretaría de Cultura como el museo local, es un indígena aconflictivo, estático, cristalizado tanto en las ruinas arqueológicas de la zona como en las piezas expuestas en el museo. Así por ejemplo, en el folleto entregado por la Secretaría a los turistas, en ningún momento se habla de la feroz resistencia de los indígenas del valle contra el Inca o contra los españoles. La ritualización que hacen de este patrimonio los sectores hegemónicos «ocultan la heterogeneidad y las divisiones de los hombres representados. Es raro que un ritual aluda en forma abierta a los conflictos entre etnias, clases y grupos.» (García Canclini, 1995: 179).

En este punto es interesante preguntarnos: ¿esta tipificación identitaria de parte de los sectores hegemónicos deja espacio a elaboraciones u apropiaciones alternativas de parte de los pobladores? Para responder a esta pregunta es necesario retomar cuáles son las características que definen, según sus propios actores, al ser santamariano.

Una de las características que apareció con más fuerza y distintividad en los discursos analizados 14 es, contradiciendo la cristalización propuesta desde los organismos oficiales, la supuesta rebeldía de los santamarianos. Esa rebeldía es relacionada por ellos directamente con la historia colonial, en particular con la resistencia indígena que ellos suponen que los une al pasado — «esa sangre india que a veces nos sale»— y que por ende define o de la cual se desprenden muchas otras características: la autonomía, la independencia, la singularidad, la solidaridad. Es decir, el pasado del lugar los une a los santamarianos en una historia de rebeldías y confrontaciones, este pasado les sirve no sólo para delimitar su propia identidad, sus sentidos de pertenencia, sino que a partir de él recortan la figura del «otro» del cual se diferencian y al cual se contraponen. Como ya lo dijimos, el «otro» por antonomasia es el «catamarqueño», el que vive en la capital provincial. Es interesante a su vez observar cómo los «catamarqueños» designan a los santamarianos, los Ilaman los collas. Esta designación, que tiene una carga peyorativa y hasta de estigma, es incorporada por los santamarianos a su patrimonio social, resignificada y exhibida a su vez como rasgo diacrítico de su identidad, según lo expresaron algunos informantes:

«La gente de San Fernando nos Ilaman los Collas. Ellos mismos son los que hacen las separaciones, allá los santamarianos [...] Creo que son raíces que nos van quedando de esos 130 años de guerra y de combatir, creo que eso perdura como una característica, ¿no? del santamariano, de los hombres de los valles [...]»

«[En] Santa María nos caracterizamos por ser rebeldes como nos tienen los catamarqueños o como nos dicen los Collas, o sea a Ud. quizás le suena muy raro cuando decimos los catamarqueños, pero en Santa María como que no somos catamarqueños pero bueno [...]»

La característica de la rebeldía, autoasignada como herencia del pasado indígena, constitutiva del ser santamariano y alterasignada desde Catamarca capital, nos habla de una apropiación del pasado que no es la misma que realizan la Secretaría de Cultura y el museo local. El indígena que intentan recuperar la Secretaría de Cultura y Turismo y el museo no tiene las mismas

13 La reivindicación de identidades indígenas es un fenómeno recurrente en los últimos años en el país.

14 Básicamente nuestro objeto de estudio estuvo centrado en la población asentada en el centro mismo de Santa María y en base a las entrevistas realizadas se realizaron estas interpretaciones. Será no solo interesante, sino indispensable, ampliar el objeto de estudio. Probablemente existan muchos otros discursos alternativos al discurso hegemónico. 
Apropiaciones y usos del pasado. Historia y patrimonio en el valle Calchaquí

características que el indígena con el cual se identificaron los entrevistados. A la figura del indio aconflictivo, estático y cristalizado se opone la imagen del indio rebelde, luchador y opositor a las huestes españolas.

\section{PALABRAS FINALES: REPENSANDO LAS POLÍTICAS CULTURALES}

Las tradiciones, los usos, las costumbres, el patrimonio, la historia, el pasado, son ingredientes primordiales a la hora de construir una identidad. Así como la identidad es parte de un proceso dinámico, cambiante y flexible, también sus elementos fundantes lo son. Las tradiciones, el patrimonio, la historia y fundamentalmente la memoria, se construyen o modelan desde el presente. Así como no hay culturas puras, auténticas, estáticas, vírgenes, tampoco hay identidades que tengan esas características. La construcción o valoración selectiva de algunos componentes —elevándolos al rango de verdaderos o auténticos—, en detrimento de otros es, casi siempre, expresión de los sectores hegemónicos.

El criterio de autenticidad se torna peligroso cuando es utilizado como eje fundacional de las políticas culturales que se llevarán a cabo en un determinado lugar. Creer que la Pachamama que reclaman los pobladores de Santa María es menos auténtica y pura que aquella construida por el escultor Guzmán a pedido de la Secretaría de Cultura, es caer en un razonamiento falaz. Nos preguntamos junto con García Canclini:

«¿̇...] qué es lo propio de una sociedad, lo que una política cultural debe favorecer? [...] Las políticas culturales menos eficaces son las que se aferran a lo arcaico e ignoran lo emergente» (García Canclini, 1995: 184-185)

Lo emergente, en nuestro caso, son las respuestas, identidades, pasados y memorias reelaboradas, disputadas y alternativas al discurso dominante. El pasado, que es el elemento sobre el cual hicimos hincapié en este trabajo, es apropiado de diversas maneras por distintos sectores de la sociedad santamariana y por supuesto también en diferentes momentos. Esas apropiaciones no son ni más ni menos verdaderas, son simplemente diferenciales. Entre esas diferencias, inclusiones y exclusiones, bien puede señalarse que a la vez que desconocen detalles del compulsivo traslado de muchos de los pobladores originarios de la región, también ignoran las condiciones de su repoblamiento, en buena medida integrado por familias que provenían de Atacama y otras del sur de Bolivia. El estigma de «collas», con el que los calificarían los de la capital de la provincia, podría tener su raíz, aunque olvidados sus fundamentos, en este repoblamiento iniciado a fines del siglo XVII y sobre todo en el siglo XVIII. De esta forma, se «falsean» sus orígenes y se idealiza a un indígena que ya no existe en los mismos términos que antes. Podría usarse, entonces, la frase de un personaje de la última novela de Umberto Eco:

«Cuidado, no te pido que testimonies lo que consideras falso, [...] sino que testimonies falsamente lo que crees verdadero». (Eco, 2001: 59) 


\section{Referencias citadas}

AAVV, 1960 - Investigaciones arqueológicas en el valle de Santa María, 126 p.; Rosario: Instituto de Antropología - Facultad de Filosofía y Letras, Universidad del Litoral.

ANTONIONE, A., 1964 - Formas de pago en una comunidad rural del siglo XVIII. Anuario del Instituto de Investigaciones Históricas, 7: 321-328.

BARTH, F., 1969 - Introduction. In: Ethnic Groups and their Boundaries (Barth, F., ed.): 9-38; Boston: Little Brown.

BRIONES, C. \& CARRASCO, M., 1996 - La tierra que nos quitaron, 296 p.; Buenos Aires: Grupo Internacional de Trabajo sobre Asuntos Indígenas.

CIGLIANO, E., (director) 1962 - El Ampajanguense, 175 p.; Rosario: Instituto de Antropología - Facultad de Filosofía y Letras, Universidad del Litoral.

ECO, U., 2001 - Baudolino, 531 p.; Barcelona: Ed. Lumen.

GARCíA CANCLINI, N., 1995 - Culturas híbridas, 361 p.; Buenos Aires: Editorial Sudamericana.

HOBSBAWN, E., 2000 - Introduction: Inventing Traditions. In: The invention of tradition: 1-14; United Kingdom: Cambridge University press.

LORANDI, A., (comp.) 1997 - El Tucumán Colonial y Charcas, t. I, 367 p., t. II, 299 p.; Buenos Aires: sección Etnohistoria, Instituto de Ciencias Antropológicas - Facultad de Filosofía y Letras, Universidad de Buenos Aires.

LORANDI, A. \& R. BOIXADÓS, 1987-1988 - Etnohistoria de los valles Calchaquíes en los siglos XVI y XVII. Runa, 17-18: 263-419.

LORANDI, A. M. \& SCHAPOSCHNICK, A., 1990 - El culto de la Virgen del Valle de Catamarca y la incorporación de los indígenas al sistema colonial. Journal de la Societé des Américanistes, 76: 177-198.

MEISTER, A., PETRUZZI, S. \& SONZOGNI, E., 1963 - Tradicionalismo y cambio social. Estudio de área en el Valle de Santa María, 128 p.; Rosario: Facultad de Filosofía y Letras, Universidad Nacional del Litoral.

QUIJADA, M., 2001 - El paradigma de la homogeneidad. In: Homogeneidad y Nación. Con un estudio de Caso: Argentina, siglos XIX y XX (Quijada, M., Bernand, C. \& Schneider, A., eds.): 15-47; Madrid: Consejo Superior de Investigaciones Científicas Centro de Humanidades. Instituto de Historia.

RASINI, B., 1962-1963 - El censo de 1771. Anuario del Instituto de investigaciones históricas, 6: 43-57.

RASINI, B., RUGGERONI, D. \& CASAÑAS, O., 1962-1963 - La población de Santa María. Anuario del Instituto de investigaciones históricas, 6: 41-42.

RATIER, H., 1988 - Indios, gauchos, y migrantes internos en la conformación de nuestro patrimonio social. Índice, 1: 26-51.

RODRÍGUEZ MOLAS, R., 1982 - Historia social del gaucho, 185 p.; Buenos Aires: Centro Editor de América Latina.

RUGGERONI, D., 1962-1963 - El padrón militar de 1812. Anuario del Instituto de investigaciones históricas, 7:13-30.

RUGGERONI, D., 1964 - Un siglo de luchas por la tierra y el agua Santa María (Catamarca, 1771-1871). Anuario del Instituto de investigaciones histórica, 6: 59-110. 